https://doi.org/10.7559/gestaoedesenvolvimento.2019.382

Data de receção: 23/04/2019 Data de aceitação: 17/07/2019

\title{
FAMÍLIA: ONTEM COMO HOJE, PERMANENTE EDUCADORA
}

\section{FAMILY: YESTERDAY AS TODAY, PERMANENT EDUCATOR}

\author{
Maria Martins ${ }^{1}$ orcid.org/0000-0001-5935-176X \\ Teresa Sarmento ${ }^{2}$ orcid.org/0000-0002-2371-399X \\ Sónia Alves ${ }^{3}$ orcid.org/0000-0001-7454-9707
}

\begin{abstract}
Resumo: A família, enquanto primeira instância de formação e socialização da criança, que se mantém ao longo da vida como permanente educadora, parece continuar a não suscitar o interesse que seria desejável por parte dos investigadores, pelo que continua a ser percecionada um pouco como "caixa negra”, ou seja, cujo funcionamento fica registado nos seus educandos mas oculto em termos públicos. Neste texto realiza-se uma abordagem à instituição familiar em termos de conceptualização, funções e sucessivas recriações estruturais, procurando-se contribuir para uma melhor apreensão da complexidade do fenómeno educativo, assumindo a imprescindibilidade da família nesse processo e o "peso imensurável que tem no desenvolvimento das pessoas" (Caeiro, 2005:21). Numa postura reflexiva, é apresentada uma análise em torno das várias tipologias familiares - da mais tradicional às pós-modernas - com destaque para as funções que socialmente sempre lhe foram $e$ continuam a ser atribuídas.
\end{abstract}

${ }^{1}$ Docente do Agrupamento de Escolas Infante D. Henrique-Viseu, em mobilidade estatutária para a DGE. E-mail: mariamartinssousa@gmail.com

${ }^{2}$ Professora Auxiliar do Instituto de Educação - Universidade do Minho. E-mail: tsarmento@ie.uminho.pt

${ }^{3}$ Docente do AE de Oliveira do Hospital, representante do CFAE Coimbra Interior na Equipa da Região Centro para a Autonomia e Flexibilidade Curricular - Despacho n. ${ }^{\circ}$ 9726/2018, de 17 de outubro. svsalves@ gmail.com 
Palavras-chave: Família(s), Educação, Mudanças sociais

\begin{abstract}
The family, as the first instance of formation and socialization of the child, who remains as a lifelong permanent educator, seems to continue not to attract the interest that would be desirable on the part of the investigators, reason why it continues being perceived a little like a "black box", that is, whose operation is registered in its students but hidden in public terms.

In this text the family institution is approached in terms of conceptualization, functions and successive structural re-creations, trying to contribute to a better apprehension of the complexity of the educational phenomenon, assuming the indispensability of the family in this process and the "immeasurable weight it has in the development of people "(Caeiro, 2005: 21). In a reflexive posture, an analysis is presented around the various family typologies - from the more traditional to the postmodern ones - with emphasis on the social functions that have always been and continue to be attributed.
\end{abstract}

Keywords: Family(s), Education, Socials Changes

\title{
INTRODUÇÃO
}

Como escola do sentimento, a família é insubstituível

(Oliver Reboul: 2000)

Falar de família é falar de todos e de cada um de nós. No entanto, e como sabemos, a cada um a sua vivência e experiência familiares, porque a cada um a sua família. Assim, como lembra Leandro (2001: 39), a família tornou-se um conceito polissémico, vivido de forma diferenciada pelos seus membros, dada a sua grande diversidade de estruturas, organizações e representações, bem como de tipologias de relações estabelecidas entre os seus elementos, sendo mais adequado falar-se em "famílias" quando nos referimos a esta instituição. 


\section{FAMÍLIA: CONCEITO POLISSÉMICO}

Segundo Leandro (2001: 38), etimologicamente, a noção de família tem origem no vocábulo latino "famulus", que significa servidor, termo que aparece apenas no século XVII.

No Novo Dicionário Compacto da Língua Portuguesa (Silva, 1988), o vocábulo família é apresentado como significando, "no seu sentido antigo e mais genérico, um conjunto de todas as pessoas, parentes ou não, que vivem sob o mesmo tecto e sob a protecção ou dependência do chefe". Enquanto agregado familiar, é considerado o grupo das "pessoas do mesmo sangue que vivem em comum, e particularmente pai, mãe e filhos" ou "pessoas ligadas por quaisquer laços de parentesco". O Dicionário Ilustrado da Língua Portuguesa (2001) vai mais longe na definição de família, apresentando esta não só como um "grupo de pessoas unidas pelo vínculo do casamento, afinidade ou adoção", mas também como um "grupo de pessoas com origem, ocupação ou outra característica comum", subentendendo-se a consideração de novas realidades estruturais da família. Em 2003, o Dicionário Houassis da Língua Portuguesa, que considera a família dentro dos parâmetros do anterior, acrescenta e especifica a possibilidade de formação de uma família a partir da união de pessoas com "convicções e interesses comuns" e apresenta algumas tipologias, cuja classificação faz depender quer do número de elementos que a constituem, quer da natureza dos laços entre eles existentes. Assim, considera poder-se falar de "família natural, família nuclear" ou, ainda, de "família substituta", a que o Dicionário Enciclopédico Português (2006) acrescenta o conceito de "família monoparental".

\section{ENQUADRAMENTO FORMAL DO CONCEITO DE FAMÍLIA: CóDIGO LEGAL PORTUGUÊS E DOCUMENTOS DE ÂMBITO INTERNACIONAL}

A família, enquanto instituição universal, é alvo de atenções e preocupações generalizadas, aparecendo referenciada em vários normativos legais, assim como em cartas e declarações emanadas de instituições de âmbito nacional e internacional. 
Consideramos importante assinalar, em primeiro lugar, a referência e a defesa da importância do papel que é reconhecido à família pela Constituição da República Portuguesa, VII Revisão Constitucional (Portugal, 2005: Cap.II, art. 67 §2). Sublinhando a importância que à família deve ser atribuída, esta é apresentada como "elemento fundamental da sociedade", consignando-lhe o "direito à proteção do Estado e à efetivação de todas as condições que permitam a realização pessoal dos seus membros". Acrescenta, ainda, que ao Estado cabe, para proteção da família, a promoção da sua "independência social e económica, (...)" e a cooperação "com os pais na educação dos filhos (...)".

Em termos jurídicos não é apresentado, propriamente, um conceito de família. Esta noção aparece definida no artigo $1576^{\circ}$ do Código Civil Português (2004), através da sua circunscrição às quatro fontes das relações jurídicas familiares que, por sua vez, abarcam grande parte das conceções de família acima referidas. Assim, o casamento, enquanto fonte de relações familiares, "é o contrato celebrado entre duas pessoas de sexo diferente que pretendem constituir família mediante uma plena comunhão de vida" (art. $1577^{\circ}$ ), definição esta alterada pela Lei $n^{\circ}$ 9/2010, de 31 de maio, a qual aprova o casamento entre pessoas do mesmo sexo, passando a ser subtraída a referência à diferença de sexos entre os celebrantes desse contrato. O parentesco (art. 1578 ) é apresentado como "o vínculo que une duas pessoas" em virtude de descendência uma da outra ou de descendência comum, sendo a afinidade (art. ${ }^{\circ} 1584$ ) "o vínculo que liga cada um dos cônjuges à família do outro e a adoção do vínculo que, à semelhança da filiação natural, mas independentemente dos laços de sangue, se estabelece legalmente entre duas pessoas" (art. ${ }^{\circ} 1587$ ).

Na opinião de Coelho e Oliveira (2003:31), esta conceptualização carece, no entanto, de algum rigor. Esclarecem estes professores da Faculdade de Direito de Coimbra que o casamento e a adoção, "como atos jurídicos, são, verdadeiramente fontes das correspondentes relações jurídicas familiares", mas que o mesmo não se pode considerar em relação ao parentesco e à afinidade, uma vez que, ao invés de fontes de relações familiares, "são, eles próprios, relações familiares, derivadas da geração ou da geração e do casamento". 
Para além das situações formais que unem duas pessoas e as definem como família, existem hoje em número crescente, situações de conjugalidade e parentalidade, logo, familiares, a descoberto do casamento mas em que os laços afetivos existem e as obrigações entre os seus membros, com o assumir das responsabilidades com os descendentes, são socialmente esperadas.

Na Declaração Universal dos Direitos da Criança (ONU, 1959), ratificada por Portugal em 1990, são enumerados os direitos fundamentais das crianças, em consonância com a Declaração Universal dos Direitos do Homem (1948) e com a Declaração de Genebra dos Direitos da Criança (1924), que todos os Estados membros da ONU se comprometem a cumprir e fazer cumprir.

Entre esses direitos, encontra-se, naturalmente, consagrado o direito à educação e formação, sendo salientada a especial responsabilidade e o direito de opção à família nesse domínio, em concordância com o que sempre the fora socialmente reconhecido. Assim, sublinhando a necessidade de afeto para o desenvolvimento pleno e harmonioso da personalidade da criança, no seu princípio $6^{\circ}$ é proclamado que ela, "na medida do possível, deverá crescer com os cuidados e sob a responsabilidade dos seus pais (...)”. Já o princípio $7^{\circ}$ sublinha o direito que a criança tem de ter acesso gratuito a uma educação de qualidade que promova a sua formação integral e, acentuando o papel fundamental e insubstituível da família no que respeita à educação dos seus membros, proclama que essa responsabilidade cabe, em primeiro lugar, aos seus pais.

Na Carta dos Direitos da Família ${ }^{4}$, dirigida não só aos Governos, às Organizações Internacionais, às famílias e à Igreja, mas a todas as pessoas no sentido de se comprometerem a pugnar para que os direitos da família sejam protegidos, são formulados os direitos fundamentais inerentes a esta "sociedade universal que é a família", expressos anteriormente, na sua maioria, em documentos quer da Igreja quer da Comunidade Internacional.

\footnotetext{
${ }^{4}$ Apresentada pelo Conselho Pontifício para a Família em 22 de outubro de 1983, responde ao voto formulado pelo Sínodo dos Bispos de 1980, para estudar o tema "O papel da família cristã no mundo contemporâneo”, aprovado pelo Papa João Paulo II.
} 
No preâmbulo desse documento é evidenciada a importância atribuída à família no que diz respeito à construção de uma sociedade equilibrada e justa. A família, considerada por esses referenciais como uma "sociedade natural", constitui, "mais do que uma unidade jurídica, social e económica, uma comunidade de amor e de solidariedade", à qual é atribuído um papel insubstituível na transmissão de "valores culturais, éticos, sociais, espirituais e religiosos", fundamentais para o desenvolvimento harmonioso dos seus elementos e da própria sociedade. Desta forma, considera-se que o Estado e as organizações internacionais têm a responsabilidade de proteger a família através da implementação de medidas adequadas, não só políticas, mas também económicas, sociais e jurídicas.

No artigo $3^{\circ}$, alínea c), da Carta dos Direitos da Família, é reconhecido à família o direito de assistência por parte da sociedade, no que se refere à procriação e educação dos seus filhos, acrescentando-se no mesmo artigo que as famílias numerosas não devem ser discriminadas e têm o direito a uma ajuda adequada.

$\mathrm{O}$ artigo $5^{\circ}$ refere-se à educação, sublinhando que, "pelo facto de terem dado vida aos seus filhos", os pais devem ser reconhecidos como os seus "primeiros e principais educadores", especificando-se na alínea a) que "os pais têm o direito de educar os seus filhos conforme as suas convicções morais e religiosas, (...) as tradições culturais (...)", devendo receber da sociedade "o apoio e assistência necessários para realizar de modo adequado a sua função educadora".

Denotando preocupações sociais no que respeita à necessidade de abertura da escola à participação ativa dos pais, na alínea e) do mesmo artigo é feita referência à importância da relação entre a escola e a família, considerando que:

“ $\mathrm{O}$ direito primário dos pais à educação dos seus filhos deve ser tido em conta em todas as formas de colaboração entre pais, professores e instituições escolares, particularmente nas formas de participação destinadas a dar voz aos cidadãos no que respeita ao funcionamento das escolas, bem como na elaboração e aplicação das políticas educativas". 
A importância da família deve ser reconhecida por todos os setores da sociedade, pelo que tem, segundo esta carta, o direito a ser valorizada e fortalecida também pelos meios de comunicação social, através da defesa e promoção públicas dos seus valores fundamentais.

Na perspetiva do Instituto de Política Familiar ${ }^{5}$, a família, enquanto sociedade natural pré-existente ao Estado ou a qualquer outra comunidade, constitui a célula base da organização e desenvolvimento sociais, assistindo-lhe direitos que considera inalienáveis. À luz dos parâmetros que norteiam a atuação e marco de referência desta instituição, a família, para além de uma unidade jurídica, social e económica, é o espaço que corresponde à vida, transmissão e construção de valores, sendo insubstituível enquanto espaço ideal para o desenvolvimento da pessoa.

A família é, ainda, apresentada e percecionada como a primeira educadora e a primeira referência que transmite os valores e a cultura de um povo, constituindo-se, assim, como "cimento" de todo o sistema educativo.

Assim, seja no plano civil como nos meios religiosos, apresenta-se fundamental, hoje mais do que nunca, a implementação de políticas públicas que tenham em conta as dinâmicas próprias da família enquanto grupo social, e que promovam o reconhecimento público da dignidade que à instituição familiar é devido, por forma a facilitar o desempenho das funções específicas que lhe estão acometidas pela própria sociedade, nomeadamente no que concerne à educação dos seus descendentes. Assim, as políticas de família, entre outros requisitos, devem ter um carácter universal, porque inclusivo de todas as tipologias familiares; deve promover a família enquanto instituição específica; ter em conta as necessidades reais das famílias e reconhecer aos pais o direito e a obrigação de educar os seus filhos.

\footnotetext{
${ }^{5}$ Entidade civil e independente de âmbito internacional, estende a sua atuação a nível da União Europeia e Ibero-América. Foi criado em 2001, com a finalidade de promover a defesa da instituição familiar, nomeadamente, através da promoção de políticas familiares adequadas.
} 


\section{A FAMÍLIA EM SEDE DE INVESTIGAÇÃO}

Embora a instituição família tenha vindo a sofrer grandes alterações em termos de conceptualização, decorrentes das dinâmicas, mutações e rearranjos que se têm verificado na sua estrutura, é do senso comum percecioná-la como um grupo, mais ou menos nuclear, de indivíduos unidos por laços, habitualmente de sangue, constituindo-se como o primeiro contexto onde a criança constrói as suas iniciais experiências de interação e onde desenvolve a sua socialização primária.

Na opinião de Villas-Boas (2001: 61), a família, independentemente da sua constituição, sempre poderá ser entendida como um sistema, uma vez que ela não é o resultado do somatório dos elementos que a constituem, antes se apresentando como o produto das interações entre os seus membros, nomeadamente no que respeita a afetos, a tempo de contacto com os adultos ou ao desenvolvimento da auto imagem, fatores que considera determinantes para o reforço da coesão familiar.

Para Ballenato (2009: 16-17), especialista em Psicologia Educativa, "a infância é o período de treino mais importante para se aprender a viver o resto da vida", sendo a família que tem a responsabilidade de criar os alicerces para um desenvolvimento global harmonioso da criança. Lembra o autor, ao realçar o carácter radicalmente determinante da experiência vivenciada em família, que "desde o nascimento, a criança é um ativíssimo recetor de estímulos" e muito do que se passará no seu futuro está altamente condicionado por este primeiro período da sua experiência vital.

Seja qual for a sua estrutura, face à escola, a família deverá ser sempre entendida como a instância à qual cabe a primeira e permanente responsabilidade pela educação e formação dos seus educandos. Concordamos com Dias (2000: 95) ao afirmar que, sendo a família o primeiro espaço de "socialização e transmissão de valores, nenhuma instituição, por mais perfeita que seja, a pode substituir”.

A par destas afirmações, não podemos deixar de reconhecer que atribuir as responsabilidades educativas (quase) exclusivamente à família é ignorar a realidade social. A sociedade atual, como sabemos, está organizada de forma complexa, com organização de ritmos de vida que pouco se compadece com a existência de crianças. $O$ afastamento geográfico dos jovens casais em relação às suas famílias de origem, os 
processos de urbanização que isolam as famílias em unidades nucleares fechadas, as dificuldades de articulação entre horários e as leis de trabalho que pouco ou nada atendem aos direitos das crianças e obrigações dos pais, faz com que as crianças sejam entregues a instituições aos quatro meses de idade, passando cerca de oito a dez horas diárias afastadas dos progenitores, o que justifica que as obrigações educativas, nos seus aspetos de socialização primária, tenham que ser efetivamente assumidas em colaboração pelos pais e pelos agentes educativos com quem as crianças passam grande parte do seu tempo.

\section{ESTRUTURAS FAMILIARES E MUDANÇAS SOCIAIS: DO MODELO TRADICIONAL À PLURALIDADE DE FORMATOS CONTEMPORÂNEOS}

A família deve ser hoje percecionada num contexto de pluralidade e diversidade estrutural e funcional, sendo as alterações no seu seio o reflexo das aceleradas mudanças operadas na sociedade. Efetivamente, como "primeiro grupo humano organizado e como unidade base da sociedade” (Dias, M. O. , 2000: 81) e comunidade que pré-existe ao Estado, é no contexto das mudanças sociais que a família deve encontrar as explicações para as suas transformações ao longo dos tempos.

Sendo que todos os tempos conheceram mudanças, certo é que a sociedade atual, pelas suas descontinuidades e aceleradas mutações, tem tido profundas repercussões na evolução da composição da família e, sobretudo, nas dinâmicas e relações entre os seus elementos. Contudo, as primeiras grandes transformações da família estão definitivamente ligadas à constituição, desenvolvimento e expansão da sociedade industrial. Este processo envolveu radicalmente aquela instituição, quer na sua estrutura e funcionamento, quer nas suas funções e relações internas, quer, ainda, e consequentemente, nas condições de vida dos seus membros (Dias, M. O., 2000: 89-95).

Num processo de contração ininterrupta (Saraceno, 1992: 23), a família tradicional múltipla, dita ocidental, a que corresponde um grupo alargado de pessoas de várias gerações, evolui para a família conjugal moderna, constituída apenas pelos progenitores e seus descendentes, passando este modelo a prevalecer nas modernas sociedades ocidentais 
industrializadas. Segundo a literatura, todas as transformações subsequentes na estrutura familiar se operam sobre este formato de família nuclear.

Como se disse, em cada época, uma sociedade, ao dar prioridade a determinados valores, determina modelos de convivência diferentes e, consequentemente, organizações familiares específicas. Ballenato (2009: 31-32) aponta como determinantes nas transformações familiares modernas e pós-modernas, fatores sociais que passam pela progressiva integração da mulher no mundo do trabalho, o aumento da taxa de divorcialidade, o processo de crescente urbanização das sociedades, os estilos de vida consumistas, a diminuição da taxa de natalidade, a difusão das novas tecnologias de informação e o aumento do fenómeno da imigração.

Diogo, J. M. L. (1998: 73) aponta, em primeiro lugar, "a crise económica e o desemprego", que coloca muitas famílias em situação difícil, com repercussões na escolaridade dos filhos. A autora acrescenta outros fatores, como o novo paradigma económico, a massificação do trabalho feminino, que veio reduzir o tempo disponível das mães, alterando as dinâmicas familiares; a evolução da ciência e das tecnologias, que desestruturaram as antigas conceções de família e, por conseguinte, do sentido de filiação e paternidade; a valorização da interação conjugal, que contribuiu para a existência de famílias sem filhos; o aumento dos divórcios, que potencia a intensificação das formas familiares monoparentais, consubstanciando, muitas vezes, uma situação de instabilidade emocional para as crianças. Paralelamente, foi-se assistindo a uma crescente "pluralização dos princípios morais " e opções valorativas seguidas pelas famílias. A conjugação destes fatores potenciou, nas últimas décadas, um movimento de proliferação e concomitância de múltiplos modelos de estruturas e convivências familiares, pondo em causa o modelo de família dominante até aos anos 50 do século XX.

Nesse contexto, fala-se hoje de uma crise familiar, temendo-se o seu desaparecimento. A esse propósito, a mesma autora considera que esta falta de consistência atribuída à família se deve ao facto de não haver atualmente predominância de um modelo sobre os outros, facto que vem a ser potenciado pela nostalgia da mitológica "família extensa intacta do 
passado distante e da família nuclear moderna do passado recente ”. (id.: 103).

Entre a pluralidade de formatos familiares coexistentes nas sociedades atuais, embora não haja total coincidência nas conceções e terminologias usadas pelos vários autores, sociólogos investigadores, são referidos pela literatura vários modelos, dos quais apresentamos os mais significativos, quer no que respeita à sua representatividade, quer em termos de contribuição para uma melhor compreensão do fenómeno em si.

A família tradicional, ou extensa, é descrita como sendo o modelo predominante nas sociedades anteriores à industrialização e urbanização. Constituída, como já referido, por várias gerações de descendentes e ascendentes, era caracterizada pelo elevado número de elementos. Esta realidade devia-se, segundo Dias, M. O. (2000: 92), não só à necessidade de fazer face à grande mortalidade infantil e à baixa esperança média de vida de então, mas também porque os valores da família eram tanto mais conseguidos e maior o prestígio que lhe era atribuído, quanto mais numerosa ela fosse.

A família nuclear ou simples, correspondendo ao modelo familiar resultante do já referido processo de contração progressiva do modelo anterior, é constituída por um grupo restrito de elementos, habitualmente apenas os pais e os filhos, biológicos ou adotados e, embora tenha vindo a conhecer um movimento de decréscimo, corresponde, segundo Aboim, S. (2003:17), à configuração familiar predominante nas sociedades atuais. No entanto, os processos de individualização nas sociedades modernas levaram à progressiva transformação deste modelo numa pluralidade de novos formatos familiares, nomeadamente ao aumento de casais sem filhos, às famílias unipessoais e monoparentais.

A família complexa ou alargada, quase inexistente na atualidade, especialmente em ambientes urbanos (Ballenato, 2009: 234), é o nome dado ao modelo que melhor se aproxima do modelo dito tradicional rural, nomeadamente no que respeita ao número de elementos que a constitui. Também chamada de família ampliada, este conceito de família abarca não só os membros da família nuclear, mas também os de outros parentescos, quer em termos ascendentes, quer descendentes ou colaterais (Leandro, 2001: 63), como avós, tios e primos. Para além dos membros com laços de parentesco, este tipo de agregado doméstico comporta 
atualmente outras pessoas e até outros núcleos familiares. Segundo esta autora (ibid.), um dos fatores associados a este modelo familiar é a resposta às necessidades económicas e sociais dos seus membros, fazendo com que a sua expansão ou diminuição dependa da eficiência das respostas dadas pelo Estado e instituições a essas mesmas necessidades. É justamente neste quadro que se compreende o aumento de núcleos monoparentais acolhidos nestes agregados familiares, situação que tem aumentado de incidência, contrariamente aos idosos que cada vez menos deles fazem parte.

Em sociologia da família, um agregado familiar monoparental corresponde a uma mãe ou um pai a viver sem cônjuge e com filhos dependentes a seu cargo. Sendo um modelo cada vez mais frequente, corresponde à circunstância de apenas um dos progenitores ser o responsável pelos descendentes e decorre de situações como o divórcio, a viuvez, gravidez na adolescência, o abandono por parte de um dos cônjuges ou da opção, também crescente, de maternidade a sós. Normalmente, este é um formato familiar a que estão associadas maiores dificuldades de subsistência, uma vez que apenas a um adulto cabem todas as responsabilidades económicas. Como nota Wall, K. (2003:11), tratando-se sobretudo de mães sós com os filhos, são famílias vulneráveis em termos económicos, assim como do ponto de vista das condições proporcionadas às crianças e dos cuidados que lhes são prestados. Esta vulnerabilidade provoca muitas vezes a dependência residencial, levando a que parte destas famílias tenham que viver em coabitação com outras pessoas e até com outros núcleos familiares. Em 2004 ${ }^{6}$, a Carta Pastoral da Conferência Episcopal Portuguesa, lembrando as fortes tensões a que as mudanças sociais dos últimos anos têm submetido a família, chama a atenção para o facto de o adulto responsável pela família no caso de monoparentalidade ter maior dificuldade em inserir-se no mercado de trabalho e, tendo que assumir tudo sozinho, viver com frequência num

${ }^{6} 10^{\circ}$ aniversário do Ano Internacional da Família. O ano 1994 foi proclamado, pelas Nações Unidas, o Ano Internacional da Família. O tema foi: "Família, Capacidades e Responsabilidades num Mundo em transformação" e consagrou o dia 15 de Maio como o Dia Internacional da Família, declarando a família como "a pequena democracia no coração da sociedade". 
"clima de cansaço, de tensão e de preocupações que acaba por afetar o equilíbrio de toda a comunidade familiar".

As famílias reconstruídas ou recompostas, com alguma história nas sociedades ocidentais (Lobo \& Conceição, 2003: 141), são famílias resultantes do estabelecimento de um novo vínculo conjugal após uma rutura por divórcio, separação ou viuvez, correspondendo à legitimação, por direito, de uma não primeira união. Este formato familiar, em número atualmente em crescimento, sobretudo devido ao aumento do número de divórcios, tem características especiais que decorrem da existência de uma espécie de novos laços e novas figuras de parentesco - os padrastos e as madrastas - uma vez que nela podem cohabitar descendentes de anteriores relações (Ballenato, 2009: 235). As conceções associadas às designações de madrasta e padrasto têm sofrido também grandes alterações, dado que a naturalização destas novas configurações familiares e os laços afetivos a elas associadas, são diferentes das existentes em tempos idos, em que a substituição de mãe/pai por madrasta/padrasto eram acompanhadas regularmente por sentidos negativos e até agressivos. Nessa perspetiva, Lobo (2009: 45) chama a atenção para a divisão de papéis que necessariamente acontece nas situações de recomposição familiar em que há descendentes de um ou dos dois cônjuges, nomeadamente entre os protagonistas masculinos. Lembra que os laços entre o pai biológico e os filhos podem ficar fragilizados com a separação, sendo este fenómeno socialmente relevante, dado que na maior parte dos casos os filhos ficam com a mãe. Assim, num processo de recomposição, e segundo Segalen (2004: 209), à "parentalidade biológica” é acrescentada a "parentalidade social".

As famílias homossexuais, enquanto estrutura familiar formal e legalmente considerada e instituída em Portugal a partir de 2010 (Lei no 9/2010, de 31 de maio), corresponde à situação de coabitação, união de facto ou, atualmente, casamento, entre duas pessoas do mesmo sexo. A estas famílias, não sendo reconhecido o direito de adoção pelo casal, há casos em que nelas vivem crianças, adolescentes e jovens provenientes de anteriores casamentos heterossexuais ou filhos adotados por um dos membros do casal.

Outras configurações familiares são ainda de considerar, tais como as famílias de adoção, as uniões de facto, as famílias de acolhimento ou as 
famílias comunitárias, em que pode variar, não apenas o número de elementos, mas fundamentalmente, o tipo de papéis, funções $\mathrm{e}$ responsabilidades dos seus elementos e, consequentemente, as relações entre eles.

\section{FUNÇÕES SOCIALMENTE ATRIBUÍDAS À INSTITUIÇÃO FAMILIAR: CONSERVAÇÃO E MUDANÇA}

Não obstante as mudanças na estrutura familiar e a coexistência de uma multiplicidade de modelos, as finalidades da família permanecem, mantendo a sua persistência ao longo da história. Segundo Dias, M. O. (2000: 82), a família, refletindo as mudanças sociais que a arrastam para novas realidades, tenta adaptar-se, sendo considerada "uma das instituições mais persistentes no tempo".

À família, como "núcleo essencial da sociedade em que vivemos" e enquanto "quadro mais favorável para a educação das crianças e dos jovens e para a sua inserção na vida" (Porto, 2005: 15), sempre foi socialmente atribuído um considerável número de funções e responsabilidades em relação aos seus membros, nomeadamente aos seus descendentes.

Na opinião de Dias, M. O. (2000: 93-94), embora se verifiquem várias orientações na definição e reconhecimento das funções da família, existe consenso acerca das funções básicas que a mesma deve desempenhar. $\mathrm{Na}$ convicção de que cada uma dessas funções assume novas evidências, são atribuídas à família: a função económica, agora muito mais ligada ao consumo do que à anterior produção; a função biológica ou reprodutora, caracterizada pelo princípio da parentalidade responsável que se traduz, atualmente, no número reduzido de filhos; a função protetora, hoje partilhada pela família com outras instituições; a função educativa, igualmente partilhada com organizações como a escola, e que se constituem como estruturas apoiantes tanto quanto competidoras. Por fim e cada vez menos, a função cultural, uma vez que hoje é desempenhada maioritariamente pelos meios de comunicação e pela escola, entre outros.

Partindo da premissa de que a família é a instituição social mais universal, segundo Ballenato (2009: 233), ela pode ser constituída por "pessoas unidas por vínculos de sangue, pelo matrimónio, adoção ou 
convivência", daí decorrendo as especificidades que caracterizam cada modelo familiar. No entanto, para lá dessas diferenças, o autor recorda que a coabitação, a responsabilidade económica, a afetividade, a reprodução, bem como a proteção, socialização e educação dos seus descendentes, são características e funções que, embora em diferentes graus de efetividade, se mantêm em todos os modelos.

Reboul (2000: 31) considera que a família não sucumbiu às críticas que lhe têm sido feitas, antes se adaptou, tendendo a evoluir oposta e simultaneamente, para a família monoparental e para a família alargada em comunidade, formas em que são preservadas e até reforçadas duas funções fundamentais: a função protetora e a função educativa.

É nesta última função educativa que se inscreve a relação entre a família e a escola, por nela se cruzarem responsabilidades e interesses mútuos.

\section{FAMÍLIA: DE "CAIXA NEGRA" AO RECONHECIMENTO DAS SUAS ESPECIFICIDADES}

Relvas et al. (2000: 10-11), num conjunto de estudos de carácter exploratório sobre algumas tipologias familiares atuais, consideram que o reduzido número de estudos sobre a família, em Portugal, faz com que esta continue a ser considerada como uma espécie de "caixa negra”, não permitindo olhar estas novas formas familiares sem enviesamentos. Contudo, as autoras afirmam a sua convicção de que este século, a avaliar pelo recente interesse de investigadores e clínicos, trará um outro espaço a todas estas famílias, no sentido de as considerar, "já não por comparação, oposição ou défice face a uma família padrão ”, mas sim no (re)conhecimento, respeito e integração das suas especificidades.

No contexto deste artigo, convém registar que é com esta pluralidade e heterogeneidade de tipologias e modelos familiares que a escola tem que se relacionar, facto que contribui, em larga medida, para a enorme e reconhecida complexidade que caracteriza essa relação, asseverando Gonçalves, A. e Ribeiro, C . (2016, p. 214) constituir-se esta como "uma relação complexa e multifacetada". A este propósito, parece-nos pertinente referir o raciocínio de Sá, V. (2004: 110) que, ao discorrer sobre as tipologias de envolvimento dos pais apresentadas segundo a perspetiva 
da escola, denuncia e critica, nessa mesma tipificação, o não reconhecimento das profundas diferenças nos formatos familiares. Acrescenta este autor que essa subtração leva a que seja ignorada a desadequabilidade de certas formas de envolvimento que, em último caso, podem "ir em contra-corrente" em relação a essas mutações familiares.

\section{REFLEXÃO FINAL}

Em termos de síntese, apontamos a pertinência de se (re)pensar a relação das escolas com as famílias atendendo à realidade múltipla existente, assumindo que as finalidades e as funções destas instituições são diversas mas complementares, e reconhecendo a pertinência da colaboração educativa e participada entre famílias, crianças e professores.

Sendo a criança/aluno o centro do processo educativo em que convergem escolas e famílias, impõe-se que entre as duas se estabeleça um permanente processo de diálogo, de escuta mútua e de definição conjunta de princípios. Que, na observância do direito de participação democrática e do dever de uma cidadania responsável, se respeitem os seus espaços não convergentes, através de uma cultura de comunicação, partilha e corresponsabilidade, de forma a que a desejável sociedade de paz, de justiça e de solidariedade se (re)construa permanentemente.

Os movimentos de alteração a nível das famílias - novas composições, novas dinâmicas - exigem que também as escolas introduzam novas estratégias de abordagem às famílias e às comunidades de pertença, de forma a que se viabilizem espaços de construção colaborativa na base do reconhecimento de cada um - criança/aluno, pais, professores - enquanto co-autor da sociedade em que vivemos através da construção de percursos educativos de qualidade para todos e cada um.

\section{FONTES E BIBLIOGRAFIA}

Aboim, S. (2003). Evolução das estruturas domésticas. Sociologia, problemas e práticas, $\mathrm{n}^{\circ} 43,2003,13-30$. Recuperado em 16 de novembro de 2010 , de http://www.scielo.oces.mctes.pt/pdf/spp/n43/n43a04.pdf 
Ballenato, G. (2009). Educar sem Gritar - Pais e filhos: convivência ou sobrevivência?(5 $5^{\mathrm{a}}$ ed.). Lisboa: Esfera dos Livros.

Caeiro, T. (2005). Abertura de seminário. In Concelho Nacional de Educação (Org.). Educação e Família, 21-24. Lisboa: CNE.

Código Civil Português. (2004). Direito da Família. Coimbra: Livraria Almedina.

Coelho, F. P. e Oliveira, G.(2003). Curso de Direito da Família. (3ª ed., Vol. I). Coimbra: Coimbra Editora.

Conselho Pontifício para a Família (1983). Carta dos Direitos da Família. Conferência Episcopal Portuguesa (2004). Carta Pastoral. Recuperado em 2 de abril de 2019, de

http://www.conferenciaepiscopal.pt/v1/apresentacao-da-cartapastoral

Dias, M. O. (2000). A família numa sociedade em mudança: problemas e influências recíprocas. Gestão e Desenvolvimento, nº 9, 81-102.

Diogo, J. M. L. (1998). Parceria escola-família: A caminho de uma Educação participada. Porto: Porto Editora.

Gonçalves, A. e Ribeiro, C. (2016). O PAPEL DOS PAIS NA ESCOLARIZAÇÃO DOS FILHOS COM PERTURBAÇÃO DA APRENDIZAGEM ESPECÍFICA COM DÉFICE NA LEITURA. Revista Gestão e Desenvolvimento, 24 (2016), 213-230.

Leandro, M. E. (2001). Sociologia da família nas sociedades contemporâneas. Lisboa: Universidade Aberta.

Lei $n^{\circ}$ 9/2010, de 31 de Maio (Aprova o casamento entre pessoas do mesmo sexo).

Lobo, C (2009). Parentalidade, fratrias e relações intergeracionais nas recomposições familiares. Sociologia, Problemas e Práticas, $\mathrm{n}^{\circ} 59$, 45-74.

Lobo, C e Conceição, C. P. (2003). O recasamento em Portugal. Sociologia, Problemas e Práticas, no 42, 141-159.

ONU. (1948). Declaração Universal dos Direitos do homem. Organização das Nações Unidas.

ONU. (1959). Declaração Universal dos Direitos da Criança. Organização das Nações Unidas.

Portugal. (2005). Constituição da República Portuguesa, VII revisão constitucional. Lisboa: Assembleia da República. 
Porto, M. (2005). Abertura de seminário. In Concelho Nacional de Educação (Org.), Educação e Família, 15-18. Lisboa: CNE.

Reboul, O. (2000). A Filosofia da Educação. Nova Biblioteca 70. Lisboa: edições 70.

Relvas, A. P., Alarcão, M. (Coords.), Tribuna, F., Mateus, G., Silva, M. H e Vaz, C. P. (2000). Novas formas de família. Coimbra: Quarteto Editora.

Sá, V. (2004). A Participação dos Pais na Escola Pública Portuguesa: Uma abordagem sociológica e organizacional. Braga: Instituto de Educação e Psicologia da Universidade do Minho.

Saraceno, Chiara. (1992). Sociologia da família. Lisboa: Imprensa Universitária - editorial estampa.

Segalen, M. (2004). Sociologie de la famille ( $5^{\mathrm{a}}$ ed.). Lisboa: Terramar.

Silva, A. M. (1998). Novo dicionário compacto da Língua Portuguesa. (Vol. III, $4^{\mathrm{a}}$ ed.). Mem Martins: Editorial Confluência.

Wall, Kain. (2003). Famílias monoparentais. Sociologia, problemas e práticas, 2003, 51-66. Recuperado em 18 de Agosto de 2010, de http://www.scielo.oces.mctes.pt/pdf/spp/n43/n43a04.pdf

Wall, Kain. (2003). Famílias no Censo 2001: estruturas domésticas em Portugal. Sociologia, problemas e práticas, Set. 2003, nº 43, 9-11. Recuperado em 16 de Agosto de 2010 de http://www.scielo.oces.mctes.pt/pdf/spp/n43/n43a04.pdf 